BMJ Open Sport \&

Exercise

Medicine

To cite: Nathan JA, Davies K, Swaine I. Hypermobility and sports injury. BMJ Open Sport \& Exercise Medicine 2018;4:e000366. doi:10.1136/ bmjsem-2018-000366

Accepted 3 October 2018

\section{Hypermobility and sports injury}

Joseph Alexander Nathan, ${ }^{1}$ Kevin Davies, ${ }^{1}$ Ian Swaine ${ }^{2}$

\section{ABSTRACT}

Objective To determine whether there is an association between hypermobility and sports injury.

Methods A quantitative observational approach using a cross-sectional survey was adopted. Individuals were identified as hypermobile or not. All participants were asked to complete two questionnaires: one asking demographic information and the other injury-specific. Fisher's exact test was used for statistical analysis. Results 114 individuals participated in the study, 62 women and 52 men. $26 \%$ of the participants were hypermobile. There was no significant association between hypermobility and sports injury $(p=0.66)$. There was a significant increase in joint and ligament sprain among the non-hypermobile $(\mathrm{NH})$ group covering all sports $(p=0.03)$. Joint dislocation was found exclusively among hypermobile individuals. The duration of injury in hypermobile individuals was higher than NH. The use of oral painkillers or anti-inflammatories in the semiprofessional group was greater than the general population.

Conclusion Hypermobility is relatively common among individuals, and there is a lot of anecdotal evidence associating it with increased rates of injuries. This project finds that $\mathrm{NH}$ individuals are more likely to sustain a ligament or joint sprain in sports. This is due to increased joint laxity and flexibility preventing injury. There were important limitations to this study which will be addressed in further work. These include assessing for pauciarticular hypermobility and focusing on one sport to investigate its association with sports injury in those who are hypermobile or not. It would also be important to focus on one specific joint, assessing its flexibility and association with injury.

\section{INTRODUCTION}

(c) Author(s) (or their employer(s)) 2018. Re-use permitted under CC BY-NC. No commercial re-use. See rights and permissions. Published by BMJ.

${ }^{1}$ Brighton and Sussex Medical School, Rheumatology, BSMS Teaching Building, University of Sussex, Brighton, UK ${ }^{2}$ Faculty of Engineering and Science, Life and Sports Sciences, University of Greenwich, London, UK

Correspondence to Joseph Alexander Nathan; josephnathan@doctors.org.uk
Joint hypermobility $(\mathrm{JH})$ is an extremely heritable condition in which the joints have a range of motion beyond normal limits. ${ }^{1}$ The prevalence of hypermobility declines with age, falling from $34 \%$ in those aged 20-30 years to $18.4 \%$ in those aged 60 years or older. ${ }^{2}$ The prevalence is greater in women than in men, and a 2:1 ratio is generally observed. ${ }^{3} \mathrm{JH}$ is a condition that is seen frequently in healthy individuals who do not have complaints. It is important to differentiate this from joint hypermobility syndrome, which is a recognised rheumatological condition that arises when a hypermobile joint is associated with arthralgia, soft tissue injury or

\section{What are the new findings?}

There was a reduced likelihood of sustaining a joint or ligament sprain in individuals who were hypermobile ( $p=0.03$ ), and this is thought to be due to increased joint laxity and range of movement within the joint.

- This can be a protective factor for injury in many sports, and individuals who are hypermobile may also be attracted to certain sports as the likelihood of injury is less.

- Regular stretching may increase flexibility, and this could subsequently reduce rates of injury in those that are less flexible.

- The timeframe of injury in hypermobile individuals was on average greater than non-hypermobile individuals, and this may indicate that hypermobile individuals sustain more severe injuries compared with those who are not.

- Awareness of this may help hypermobile individuals seek injury prevention strategies.

How might it impact on clinical practice in the near future?

This paper does not find an increased rate of sports injuries in hypermobile individuals compared with those who are not $(\mathrm{p}=0.66)$.

- This can encourage hypermobile participants to engage in sports without a concern that they are more likely to sustain injury.

- There were important limitations to this study which will be addressed in further work.

- These include assessing for pauciarticular hypermobility and focusing on one sport to investigate its association with sports injury in those who are hypermobile or not.

- It would also be important to focus on one specific joint, assessing its flexibility and association with injury.

joint instability. ${ }^{4}$ Hypermobility is diagnosed as a Beighton score of 4 or above. ${ }^{5}$

Inherent hypermobility can attract individuals to certain sports, as activities are easier to perform. However, it can also carry some disadvantages as the rates of injury in certain sports are shown to be higher. ${ }^{6}$

Anecdotal evidence suggests that being hypermobile increases the likelihood of sustaining injury in contact sports, while it may prevent injury in non-contact sports. 
This may be because hypermobile joints are unstable in nature due to their increased range of movement and subsequently reduced core stability. Subsequently, when impact occurs, they are not able to direct the force through the joint in a stable manner. In contact sports this causes joints to be in unstable positions due to their hypermobile nature, and when exposed to physical contact leads to injury. One may also hypothesise that JH may prevent injury in sports that require increased flexibility as there is less stress put through an already flexible joint. An example that highlights this is that if a runner misplaces their footing a flexible joint is able to move to the desired direction without sustaining injury. However, in a less flexible joint, an injury may occur. Hypermobile individuals may also be attracted to certain sports that require increased flexibility as certain movements are easier to perform, for example, hypermobility and being a gymnast. ${ }^{7}$ It has also been suggested that training can increase flexibility.

\section{Beighton score}

The Beighton score is an edited version of the CarterWilkinson scoring system, which was used as an indicator of widespread hypermobility. A Beighton score is a useful research tool to indicate generalised hypermobility. It is straightforward to perform clinically, but a high Beighton score does not mean an individual has hypermobility syndrome. Signs and symptoms also need to be present before hypermobility syndrome can be diagnosed. ${ }^{8}$ Likewise, a low score should be considered with caution as hypermobility can present as chronic pain in joints that are not assessed by the Beighton score, for example, neck, jaw, back or shoulder pain. ${ }^{9}$ Medical professionals vary in their interpretation of the results, with some accepting as low as 1 out of 9 as being hypermobile. The general consensus is that a score of 4 or more defines hypermobility. ${ }^{10}$

\section{Literature review}

A literature search was conducted using PubMed, CumulativeIndex to Nursing and Allied Health Literature, Medline and Google Scholar. The search terms set were 'hypermobility', 'sport' and 'injury', and only peer-reviewed journals were included in the results. In addition, only papers from year 2000 and those that were published in English were selected. Abstracts were not included in the search results.

There does not appear to be a clear consensus that identifies an association between hypermobility and sports injury. Some papers suggest there is one; however, there is limited statistical evidence to support the finding. ${ }^{71-14}$ Other papers suggest that being hypermobile may prevent injury in certain sports. ${ }^{911} 1516$ Most research finds no association at all. ${ }^{1517} 18$ Most papers analysed a single sport.

\section{Pilot study and focus group}

A small-scale pilot study and focus group was performed before commencement of data collection. There were two aims: the first was to identify whether the questionnaires designed asked appropriate questions and were clear in the instruction (this was fed back through the focus group), and the second was to determine whether the results can be analysed using the appropriate statistical test. The focus group provided an insight into how individuals thought and provided a deeper understanding of the area being studied. Focus groups can also be used for feedback and integration of a study design. ${ }^{19}$

\section{METHODOLOGY}

Below are the individuals who participated in the research project:

- University of Sussex medical student sports teams, including football (male), hockey (male and female), rugby (male) and netball (female).

- A Brighton and Hove running club (male and female).

- Individuals who were found to also participate in other sports, for example, swimming, tennis, squash and cycling.

University of Sussex sports teams were invited through contact with the individual sports team captains. Teams were met after a weekday training session and the nature of the research project was explained. Participants completed a consent form and were given a patient information sheet. A second date was arranged for data collection. At the second meeting individuals willing to participate were visited by the chief investigator, again after a training session. Their Beighton score was calculated and collected and the two questionnaires were completed. The same process was followed with a Brighton and Hove running club and semiprofessional under-21 women's football team.

\section{RESULTS}

A total of 114 participants participated, 62 men and 52 women. Running $(n=26)$ and football $(n=24)$ had the highest numbers of participants. Other sports include hockey $(n=19)$, netball $(n=17)$, rugby $(n=16)$, cycling $(\mathrm{n}=5)$, tennis $(\mathrm{n}=4)$, squash $(\mathrm{n}=2)$ and swimming $(\mathrm{n}=1)$ (see table 1). These data have also been represented as a pie chart (see figure 1).

The overall prevalence of hypermobility was $26 \%$. Twenty-two women (42\%) and eight men (13\%) were hypermobile. Hypermobility was most common in hockey and running (31.6\% and $30.8 \%$, respectively). There was a high prevalence in cycling and swimming ( $40 \%$ and $100 \%$ ) but with limited sample size (5 and 1 , respectively) (see table 2 ).

Of the total number of participants, 73 had sustained an injury over the past 2 years $(64 \%)$. This was defined as any occasion where an individual was unable to perform their chosen sport(s). Injuries were highest in rugby and running ( $75 \%$ and $73.1 \%$, respectively). All injury rates were greater than $50 \%$, except for swimming although this category involved only one participant. The overall total number of injuries was greater among the 


\begin{tabular}{lccc}
\hline Table 1 & \multicolumn{4}{l}{ Total participants in each sport } \\
\hline Sport & Men & Women & Total \\
\hline Running & 14 & 12 & 26 \\
Football & 10 & 14 & 24 \\
Cycling & 4 & 1 & 5 \\
Squash & 2 & 0 & 2 \\
Swimming & 1 & 0 & 1 \\
Rugby & 16 & 0 & 16 \\
Hockey & 11 & 8 & 19 \\
Tennis & 4 & 0 & 4 \\
Netball & 0 & 17 & 17 \\
Total & 62 & 52 & 114 \\
\hline
\end{tabular}

Table 2 Prevalence of hypermobility in each sport

\begin{tabular}{lcccc} 
Sport & Total & Hypermobile & Non-hypermobile & $\begin{array}{l}\text { Hypermobile } \\
(\%)\end{array}$ \\
\hline Running & 26 & 8 & 18 & 30.8 \\
\hline Football & 10 & 6 & 18 & 25 \\
Cycling & 4 & 2 & 3 & 40 \\
\hline Squash & 2 & 0 & 2 & 0 \\
\hline Swimming & 1 & 1 & 0 & 100 \\
\hline Rugby & 16 & 2 & 14 & 12.5 \\
Hockey & 11 & 6 & 13 & 31.6 \\
\hline Tennis & 4 & 1 & 3 & 25 \\
Netball & 0 & 4 & 13 & 23.5 \\
\hline Total & 62 & 30 & 84 & 26.3 \\
\hline
\end{tabular}

non-hypermobile (NH) group. Sustaining a ligament or joint sprain was the most common injury in $\mathrm{NH}$ individuals (total $=38$ ), while in hypermobile participants this occurred only seven times. Sustaining a fracture was similarly common in both hypermobile and $\mathrm{NH}$ individuals ( 8 and 7 , respectively). A joint dislocation troubled three hypermobile individuals, while it did not affect those who were not. Other injuries accounted for seven injuries sustained by $\mathrm{NH}$ individuals. Other injuries included ligament rupture, tendonitis or simple overuse that resulted in significant pain which prevented further participation in the desired sport. One NH individual suffered a soft tissue laceration (see figure 2).

Fisher's exact test was used for statistical analysis. Fisher's exact test is more accurate than the $\chi^{2}$ test when the expected numbers are small. It is recommended to use Fisher's exact test when the total sample size is less than 1000 and to use the $\chi^{2}$ test when it is greater. ${ }^{20}$

A two-tailed test was used and a two by two contingency table generated to assess whether there was a significant relationship between hypermobility and sports injury. A p value of 0.74 showed that with a $95 \%$ degree of certainty there was no statistically significant relationship between hypermobility and injury (see table 3 ).

There was a statistically significant relationship between sustaining a joint/ligament sprain and not being hypermobile among runners $(\mathrm{p}=0.04)$ and all sports $(\mathrm{p}=0.03)$.

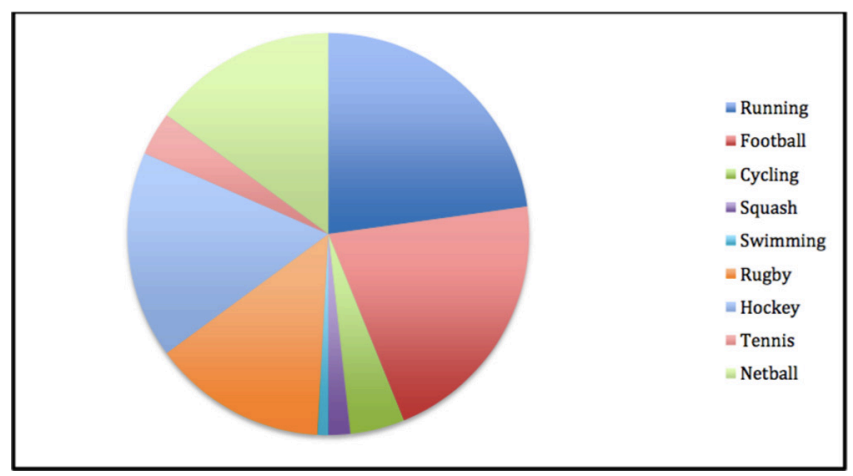

Figure 1 Total participants in each sport.
This relationship was not found in any other injury group (see table 4).

The following are other findings:

- Most hypermobile individuals were injured for greater than 2 weeks (16 out of 18), while in the NH group there appeared to be a much greater distribution in the duration of injury ( 36 out of 55 over 2 weeks).

- Twenty-three out of 114 individuals had another medical condition, most commonly asthma $(n=15)$; other medical conditions included eczema $(n=3)$, psoriasis $(n=3)$ and anxiety $(n=2)$.

- Seven of these took regular medication, five individuals with asthma took inhalers, one took medication for anxiety and one other took an antihistamine for eczema.

- On average individuals trained twice a week.

- Seventy-three out of 114 participants sustained at least one injury in the last 2 years.

- Out of a total of 73 individuals who sustained at least one injury in the past 2 years, 48 sought advice from their doctor, 28 their physiotherapist, 7 their coach, 3 their friend and 3 individuals did not seek any medical advice. (This total is greater than 73 as some sought advice from multiple specialists).

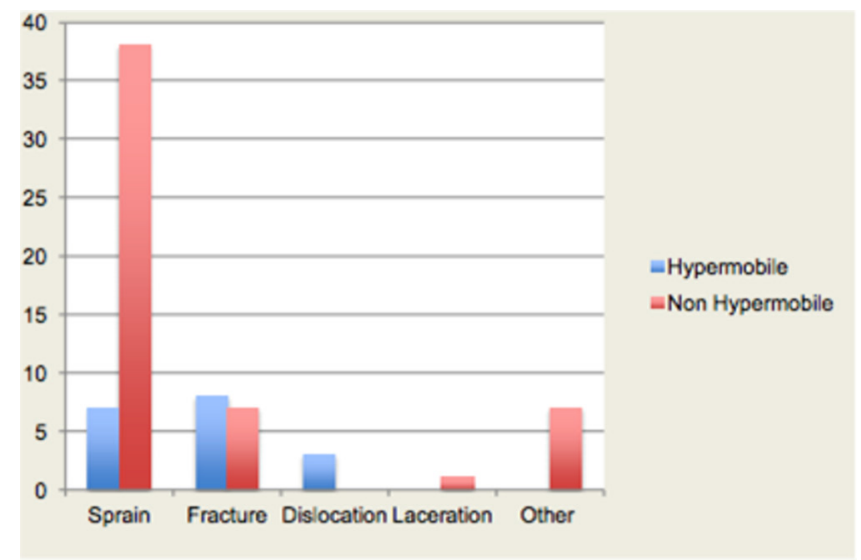

Figure 2 Injuries sustained in hypermobile and nonhypermobile individuals. 
Table 3 Contingency table of hypermobility and injury

\begin{tabular}{lll}
\hline Category & Injured & Not injured \\
\hline Hypermobile & 18 & 12 \\
Non-hypermobile & 55 & 29 \\
\hline
\end{tabular}

- Thirty-six undertook a rehabilitation programme while 37 did not.

- Twenty-one individuals who were injured took overthe-counter analgesic, for example, paracetamol. Twenty-three took ibuprofen, and 14 took both paracetamol and ibuprofen. Three individuals took a higher dose analgesic called tramadol and 12 people took no medication at all.

- Sixteen had a sports massage, 12 had an X-ray, 2 an MRI, 6 surgery and 37 required no further treatment. Below is a summary of the findings among the under-21 semiprofessional team:

- Fourteen members of this under-21 women's team participated in this study; four of these were hypermobile.

- Ten of these had sustained an injury in the last 2 years while four had not.

- Eight of those injuries were a result of a muscle or joint sprain while the remaining two involved a fracture.

- All individuals undertook a rehabilitation regimen following injury, and they all received treatment from the team physiotherapist; three also saw the club doctor.

- All injuries required a minimum of 2-4 weeks away from football $(40 \%), 50 \%$ were injured for 2-6 months, while one for more than 6 months.

- All who were injured took an anti-inflammatory (eg, ibuprofen) to help with the pain they experienced, while three of these women also took an analgesic (eg, paracetamol).

\section{DISCUSSION}

Of the total number of participants, 30 were hypermobile (26\%) and of these 22 were female and 8 were male, $42 \%$ and $13 \%$, respectively.

Runners and hockey players were the sports group that had the highest prevalence of hypermobility. One may hypothesise that certain sports require a greater degree of flexibility among joints and those that have are more attracted to participate due to reduced rates of injury.

\begin{tabular}{|c|c|c|c|}
\hline Injury & $\begin{array}{l}\text { Non-hypermobile } \\
\text { runner }\end{array}$ & $\begin{array}{l}\text { Hypermobile } \\
\text { runner }\end{array}$ & $P$ values \\
\hline Sprain & 11 & 1 & 0.04 \\
\hline Fracture & 2 & 2 & 0.56 \\
\hline Dislocation & 0 & 1 & 0.31 \\
\hline Laceration & 0 & 0 & $\begin{array}{l}\text { Not } \\
\text { applicable }\end{array}$ \\
\hline Other & 1 & 2 & 1 \\
\hline
\end{tabular}

Sustaining repeated or regular injuries in a particular physical activity can act as a deterrent and can easily lead to discouragement from further participation.

\section{Multisports analysis}

This research finds no association between hypermobility and sports injury, and this may be due to the study being a multisport analysis, whereas previous papers mainly analysed single sports.

\section{Analysis of injuries}

One of the most common complaints of injuries in the runners group is joint or muscle sprain. Nineteen of the runners sustained an injury in the past 2 years, and 12 of these were due to a muscle or joint sprain $(63 \%)$. Interestingly only one of the participants who sustained muscle or joint sprain was hypermobile. Fisher's exact test was used to determine if this was of statistical significance and a $\mathrm{p}$ value of 0.04 was generated. This association was found in all sports between hypermobility and sustaining muscle or joint sprain. This suggests that being hypermobile is a protective factor for sustaining a muscle or ligament sprain in all sports.

\section{Hypermobility and joint dislocation}

Literature suggests that one of the most common associations and complaints in hypermobile individuals is dislocation. ${ }^{21}$ When reviewing the nature of injuries in both hypermobile and NH individuals, it is noticeable that only three individuals suffered joint dislocation. Although this number is small, this supports the association.

\section{Hypermobility and duration injured}

Out of 18 individuals who were hypermobile and sustained an injury, $50 \%$ were injured for between 2 and 6 months, $39 \%$ of these between 2 and 4 weeks, and the remaining for 1 week or less. None of these individuals were injured for longer than 6 months. However in $\mathrm{NH}$ individuals $11 \%$ were injured for greater than 6 months, $15 \%$ between 2 and 6 months, $40 \%$ between 2 and 4 weeks, and $35 \% 1$ week or less. Overall $50 \%$ of hypermobile individuals were injured for more than 4 weeks, while in the $\mathrm{NH}$ group this was greater at $65 \%$. One could hypothesise that NH individuals were more likely to suffer from significant injury requiring greater time away from their sport than hypermobile individuals.

\section{Other findings}

In the literature search at the start of this project, there appears to be a recognised association between hypermobility and anxiety. ${ }^{22}$ However, among the population involved, only one individual has a diagnosis of anxiety and they are not hypermobile.

Most individuals who sustained an injury went to see their doctor, and a large number of people went to visit a physiotherapist. One suspects these findings can be explained by those who were involved in club/semiprofessional training teams. Their first contact is likely to be 
with the physiotherapist rather than the doctor as they are more closely connected to their clubs. It is interesting that some participants did not seek any medical advice and this may be due to accessibility to healthcare or health beliefs.

Pain was a common complaint in individuals following injury, and $84 \%$ took a form of pain relief, either overthe-counter paracetamol or ibuprofen or a stronger form of pain relief (eg, tramadol).

\section{Analysis of semiprofessional football under-21 women's team} One may expect that there is a higher concentration of hypermobile semiprofessional sportswomen; however, looking at this subgroup, this does not appear to be the case and seems to reflect the prevalence in the general population. The occurrence of injury also appears to be similar.

The general duration of injury in this group appears to be greater than in other sports and participants in this study. This may be due to the nature of football injuries. Because football is a high-impact sport, the injuries sustained may be more severe. All individuals who were injured took a form of medication to help with pain relief. This may suggest that medication is overprescribed in semiprofessional sportspeople, or it could suggest that due to regular contact with experienced healthcare professionals at their club they may be less reluctant to take medication.

\section{Strengths and limitations}

One significant limitation of this project was the lack of assessment of innate joint instability and the over-reliance on the Beighton scoring system for generalised JH. The Beighton scoring system does not assess many joints that are involved in sports injury, for example, shoulder, hips, ankles and feet, and this would need to be addressed in further work.

This project found that hypermobility was a protective factor for sustaining joint or muscle sprain injury while participating in contact or non-contact sports, and this relationship has not been described in other research. However, as this was a multisport analysis, it is difficult to draw any definitive conclusion from these results.

One of the limitations of this study was the self-reporting of injury. The use of imaging would help determine and define the severity of injury, for example, in muscle sprains. Another limitation was that the study mainly involved university students, and therefore the age range included is limited. Most were aged 18-29. This may capture the most hypermobile age group as it is suggested that flexibility and hypermobility reduce with age. ${ }^{4}$ It would have been interesting to note if the association between hypermobility and sports injury differed among individuals or different age groups, and whether the injuries sustained were different among the different age groups.

\section{Recommendation for further work}

It would be important to assess for pauciarticular hypermobility in further work, and this could focus on one sport and investigate its association with sports injury in those who are hypermobile or not. It would also be important to focus on one specific joint, assessing its flexibility and association with injury. ${ }^{23}$

There is a possible association between joint dislocation and hypermobility. As a recommendation for further work, one could perform a retrospective analysis in a population of individuals who sustained joint dislocation in sports and investigate if they were hypermobile or not. This project identifies that individuals who were hypermobile are less likely to obtain muscle or ligament sprains in sport. One could hypothesise that regular stretching increases flexibility, and this could subsequently reduce the rates of injury.

Further work can also include focusing on one specific sports group and injuries sustained to a particular joint. The specific flexibility of that joint will also be assessed to provide more focused data for analysis. This will provide much more worthwhile data for analysis and to provide advice for injury prevention together with focusing on strength and conditioning techniques to prevent injury. Finally, a five-part questionnaire mentioned in Juul-Kristensen et $a l \mathrm{~s}^{24}$ meta-analysis can be incorporated into initial screening.

\section{CONCLUSION}

This project found no association between hypermobility and sports injury $(\mathrm{p}=0.66)$. This may be due to the study being a multisport analysis rather than a single-sport analysis, which most papers have done. Hypermobility was found to be a protective factor for sustaining muscle or joint sprain $(\mathrm{p}=0.03)$ in all sports. Other findings were that joint dislocation was only found in hypermobile individuals and that the timeframe of injury in hypermobile individuals was on average longer than in NH individuals. This research provides a strong foundation for further work.

Acknowledgements The authors would like to acknowledge and thank all the participants of this study.

Contributors Contributorship was solely by the authors mentioned. The authors were responsible for substantial contributions to the conception or design of the work, or the acquisition, analysis or interpretation of data. In addition, the main author drafted the work and with the help of the coauthors revised it critically for important intellectual content. All authors have approved the final version and are in agreement to be accountable for all aspects of the work in ensuring that questions related to the accuracy or integrity of any part of the work are appropriately investigated and resolved.

Funding The authors have not declared a specific grant for this research from any funding agency in the public, commercial or not-for-profit sectors.

Competing interests None declared.

Patient consent Not required.

Ethics approval Ethical approval was sought from the Brighton and Sussex Medical School (R\&D reference 16/008/DAV). Participants in this study gave informed consent before their involvement.

Provenance and peer review Not commissioned; externally peer reviewed. 
Data sharing statement Additional data collected in this study are available and can be obtained by emailing the main author at josephnathan@doctors.org.uk.

Open access This is an open access article distributed in accordance with the Creative Commons Attribution Non Commercial (CC BY-NC 4.0) license, which permits others to distribute, remix, adapt, build upon this work non-commercially, and license their derivative works on different terms, provided the original work is properly cited, appropriate credit is given, any changes made indicated, and the use is non-commercial. See: http://creativecommons.org/licenses/by-nc/4.0/

\section{REFERENCES}

1. Hakim A, Grahame R. Joint hypermobility. Best Pract Res Clin Rheumatol 2003;17:989-1004.

2. Connelly E, Hakim A, Davenport S, et al. A study exploring the prevalance of joint hypermobility syndrome in patients attending a musculoaskeletal triage clinic. Physiotherapy Practice and Research 2015;36:43-53.

3. Seçkin U, Tur BS, Yilmaz O, et al. The prevalence of joint hypermobility among high school students. Rheumatol Int 2005;25:260-3.

4. Bulbena A, Duró JC, Porta M, et al. Clinical assessment of hypermobility of joints: assembling criteria. J Rheumatol 1992;19:115-22.

5. Grahame R. Joint hypermobility and genetic collagen disorders: are they related? Arch Dis Child 1999;80:188-91.

6. Hakim AJ, Cherkas LF, Grahame R, et al. The genetic epidemiology of joint hypermobility: a population study of female twins. Arthritis Rheum 2004;50:2640-4.

7. Pacey V, Tofts L, Wesley A, et al. Joint hypermobility syndrome: a review for clinicians. J Paediatr Child Health 2015;51:373-80.

8. Beighton P, Solomon L, Soskolne CL. Articular mobility in an African population. Ann Rheum Dis 1973;32:413-8.

9. McCormack M, Briggs J, Hakim A, et al. Joint laxity and the benign joint hypermobility syndrome in student and professional ballet dancers. J Rheumatol 2004;31:173-8.

10. Clinch J, Deere K, Sayers A, et al. Epidemiology of generalized joint laxity (hypermobility) in fourteen-year-old children from the UK: a population-based evaluation. Arthritis Rheum 2011;63:2819-27.
11. Weber AE, Bedi A, Tibor LM, et al. The hyperflexible hip: managing hip pain in the dancer and gymnast. Sports Health 2015;7:346-58.

12. Nicholas JA. Injuries to knee ligaments. Relationship to looseness and tightness in football players. JAMA 1970;212:2236-9.

13. Konopinski MD, Jones GJ, Johnson MI. The effect of hypermobility on the incidence of injuries in elite-level professional soccer players: a cohort study. Am J Sports Med 2012;40:763-9.

14. Collinge R, Simmonds JV. Hypermobility, injury rate and rehabilitation in a professional football squad_a preliminary study. Phys Ther Sport 2009;10:91-6.

15. Bronner S, Ojofeitimi S, Woo H. Extreme kinematics in selected hip hop dance sequences. Med Probl Perform Art 2015;30:126-34.

16. Grahame R. Joint hypermobility: emerging disease or illness behaviour? Clin Med 2013;13(Suppl 6):s50-2.

17. Jamshidi A, Faghih-Roohi S, Hajizadeh S, et al. A big data analysis approach for rail failure risk assessment. Risk Anal 2017;37:1495-507.

18. Stewart DR, Burden SB. Does generalised ligamentous laxity increase seasonal incidence of injuries in male first division club rugby players? Br J Sports Med 2004;38:457-60.

19. Morgan DL, Bottorff JL. Advancing our craft: focus group methods and practice. Qual Health Res 2010;20:579-81.

20. McDonald JH. Handbook of biological statistics. 3rd edn. USA: Sparky House Publishing, 2014.

21. Hopper DM, Hopper JL, Elliott BC. Do selected kinanthropometric and performance variables predict injuries in female netball players? J Sports Sci 1995;13:213-22.

22. Eccles J, Harrison N, Critchley H. Joint hypermobility syndrome. Psychiatric manifestations. BMJ 2011;342:d998.

23. Castori $\mathrm{M}$, Tinkle $\mathrm{B}$, Levy $\mathrm{H}$, et al. A framework for the classification of joint hypermobility and related conditions. Am J Med Genet C Semin Med Genet 2017;175:148-57.

24. Juul-Kristensen B, Schmedling K, Rombaut L, et al. Measurement properties of clinical assessment methods for classifying generalized joint hypermobility-a systematic review. Am J Med Genet C Semin Med Genet 2017;175:116-47. 